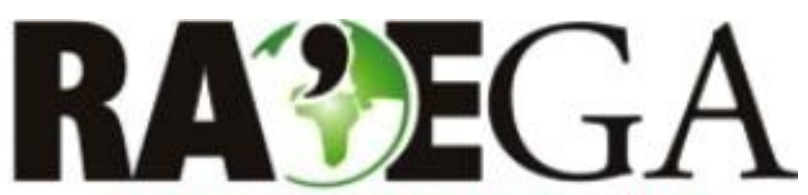

O ESPACO GEOGRÁFICO EM ANÁLISE

\title{
A INSERÇÃO DA CIDADE PEQUENA DE AMPÉRE - PR NA REDE URBANA A PARTIR DA DINÂMICA INDUSTRIAL ${ }^{1}$
}

\section{THE INSERTION OF TOWN SMALL OF AMPÉRE - PR IN URBAN NETWORK FROM INDUSTRIAL DYNAMICS}

\author{
Carlos Cassemiro Casaril \\ Universidade Estadual do Oeste do Paraná - UNIOESTE \\ Francisco Beltrão, PR, Brasil \\ e-mail: carloscasaril@yahoo.com.br \\ Fernando dos Santos Sampaio \\ Universidade Estadual do Oeste do Paraná - UNIOESTE \\ Francisco Beltrão, PR, Brasil \\ e-mail: fernandosampaio cch@yahoo.com.br
}

Recebido em: 08/06/2015

Aceito em: 02/08/2016

\section{Resumo}

O objetivo deste trabalho é analisar a inserção de Ampére - Paraná na rede urbana a partir da dinâmica de seu setor produtivo. Ampére é um centro local inserido na rede urbana de Francisco Beltrão - PR, localizada na mesorregião Sudoeste Paranaense. Rede esta que se torna cada vez mais complexa e, essa complexidade se amplia à medida que se amplia a divisão territorial do trabalho, o que, possibilita que um centro local mantenha relações não apenas com a rede urbana estruturada pela teoria das localidades centrais, mas se estruturam, ao mesmo tempo, em outra rede urbana, deste modo, um dos aspectos desta complexidade diz respeito ao fato de cada cidade situar-se em pelo menos duas redes. Por exemplo, Ampére mesmo sendo um centro local na área de influência de Francisco Beltrão nos anos 1960 e 1970, cuja dinâmica era dada, sobretudo, pela distribuição da produção rural de bens e serviços, foi nos anos 1990 e 2000 se transformando em um centro especializado na produção industrial de móveis e confecções. Deste modo, a cidade se inseriu em diversas relações que dão conta da aquisição de matérias-primas, fluxos de mão de obra, produção, distribuição da produção que alcançam todos os Estados brasileiros e uma pequena parte da produção é encaminhada para o mercado externo, não nos esquecendo, ainda que, tais relações produzem fluxos de todas as ordens, sobretudo financeiros, responsáveis, principalmente, por manter a dinâmica econômica do centro urbano.

\footnotetext{
${ }^{1}$ Agradecemos o apoio financeiro da Coordenação de Aperfeiçoamento de Pessoal de Nível Superior (CAPES), pela Bolsa do Programa Nacional de Pós-Doutorado/PNPD.
} 
Palavras-Chave: Geografia Econômica, Geografia Urbana, Rede Urbana, Ampére, Desenvolvimento Regional.

\begin{abstract}
The aim of this study is to analyze the insertion of Ampere - Paraná in the urban network from the dynamics of its productive sector. Ampere is a local center inserted in the urban network of Francisco Beltrão - PR, located in the mesoregion Southwest Paranaense. This network that becomes increasingly complex, and this complexity widens as it extends the territorial division of labor, what makes it possible that a local center maintains relationships not only with the urban network structured by the theory of central localities, but are structured at the same time, in another urban network, thus, one of the aspect of this complexity is the fact of each city be situated in at least two networks. For example, Ampere, even being a local center in the area of influence of Francisco Beltrão in the years 1960 and 1970, whose dynamics was given especially by the distribution of rural production of goods and services, was in the years 1990 and 2000 turning into a center specializing in the industrial production of furniture and clothing. Thus, the city was inserted in several relations leading to the acquisition of raw materials, labor flows, production, distribution of production that reach all Brazilian States and a small part of the production is forwarded to the external market, not forgetting though, such relationships produce streams of all orders, especially financial, responsible mainly for maintaining the economic dynamics of the urban center.
\end{abstract}

Keywords: Economic Geography, Urban Geography, Urban Network, Ampere, Regional Development.

\title{
1. INTRODUÇÃO
}

O objetivo deste trabalho é analisar a inserção de Ampére - Paraná na rede urbana a partir da dinâmica de seu setor produtivo. Conforme o último estudo denominado de Região de Influência das Cidades (REGIC) (IBGE, 2008), Ampére é um centro local inserido na rede urbana de Francisco Beltrão - PR, localizada na mesorregião Sudoeste Paranaense. A cidade conta com 13.257 habitantes, valendo destacar que a população total é de 17.308 habitantes, portanto, 76,59\% de população urbana (IBGE, 2010).

Este trabalho se justifica, sobretudo, devido à relativa ausência de pesquisas enfocando as "pequenas cidades e centros locais". Segundo Monbeig (1957, p.36) as cidades pequenas merecem ser estudadas, pois, são tão interessantes "[...] quanto as colmeias urbanas modernas e é quase sempre mais difícil precisar seu mecanismo e o ritmo calmo de sua vida do que analisar 
as engrenagens bem lubrificadas, correndo a toda velocidade, das metrópoles imponentes. [...]".

A gênese dos núcleos urbanos da Rede de Francisco Beltrão pode ser caracterizada, basicamente, pela coleta e expedição dos produtos agrícolas e pela distribuição de bens e serviços. Dessa maneira, a rede de cidades originou-se relacionada às necessidades de venda e compra de produtos pelos colonos (CORRÊA, 1970a; 1970b). Vale destacar que, Ampére se tornou município em 28 de novembro de 1961 e suas terras foram desmembradas de Capanema e de Santo Antônio do Sudoeste, tendo como foco da vida urbana a "bodega", nome dado pela população local aos pequenos comércios de "secos e molhados" (CASARIL, 2014).

Ampére (como sua rede urbana) desenvolveu uma formação social calcada na presença de pequenos proprietários rurais, vinculada a pequenos comércios e artesanato local. O complexo de atividades artesanais foi se desintegrando do campo "pari passu" e à medida que se avançava essa desintegração, prenunciavam novas atividades industriais, sobretudo, a partir dos anos 1970. Ampére despontou nesse período pela força do empresariado local que, a partir de empréstimos, poupança familiar, entre outros, investiu no setor produtivo, com destaque para o segmento moveleiro e de confecções (CASARIL, 2014).

Ao analisar a dinâmica atual do setor produtivo e suas contemporâneas interações, verifica-se que a rede urbana de Francisco Beltrão, na qual Ampére está inserida, torna-se cada vez mais complexa. E, essa complexidade aumenta à medida que se amplia a divisão territorial do trabalho (FRESCA, 2010).

O artigo foi dividido em quatro partes, sendo a introdução; os materiais e métodos; os resultados e discussões que se subdividiu em duas etapas, na primeira apresenta-se uma discussão sobre o conceito de rede urbana, a fim de permitir um entendimento da fundamentação teórica utilizada no trabalho e na segunda desenvolve-se a análise sobre a inserção de Ampére na rede urbana, apresentando a discussão sobre a gênese e a evolução das indústrias instaladas, com análises comparativas, possibilitando um entendimento de 
como a dinâmica do setor industrial contribuiu para a complexidade da rede urbana de Francisco Beltrão e possibilitou a Ampére, uma cidade local, inserirse em mais de uma rede urbana; finalizando com as considerações e referências.

\section{MATERIAIS E MÉTODOS}

Para a realização da pesquisa, alguns procedimentos metodológicos e operacionais foram utilizados, estes tanto de caráter quantitativos como qualitativos.

Os procedimentos operacionalizados dizem respeito a trabalhos de campo, uma das principais ferramentas utilizadas nas pesquisas pelos geógrafos, realizados, sobretudo, nos estabelecimentos industriais citados no artigo, e, trabalhos considerados de gabinete, como revisão bibliográfica, coleta de dados secundários em diversas instituições, como Instituto Brasileiro de Geografia e Estatística (IBGE), Ministério do Trabalho e Emprego (MTE), por meio da Relação Anual de Informações Sociais (RAIS), sem esquecer-se de pesquisa documental em jornais regionais, sempre procurando informações importantes para o desenvolvimento da pesquisa.

A fim de analisar esta determinada rede urbana, utilizou-se como perspectiva teórica a categoria de Formação Sócio-Espacial (FES) (SANTOS, 1977). A análise busca a apreensão da realidade, que apresenta múltiplas determinações, características próprias de formações sociais antigas e novas (continuidades e descontinuidades).

\footnotetext{
[...] A combinação de sucessivas justaposições produzirá, nas formações sócio-espaciais, efeitos específicos, que variam no espaço e contribuem para promover e ampliar as diversidades geográficas, pois tais processos materializam-se de maneira distinta e seletiva, assim como sofrem ajustes, em maior ou menor grau, no contato com a própria formação socioespacial, resultando, portanto, numa organização diferenciada do espaço [...] (BESSA, 2007, p.61-62, grifo nosso).
}

A essas combinações supracitadas, pode-se ainda somar um entendimento com base nas ideias de André Cholley (1964a; 1964b), que fala nas "combinações geográficas", ou seja, que o entendimento de toda realidade é formada por combinações de elementos de origens físicas, biológicas e 
humanas, o que na verdade se soma a proposta das múltiplas determinações de Karl Marx, e que, todavia, vem a se somar junto a nossa perspectiva teórica para o estudo de uma dada rede urbana.

E, a respeito da categoria de FSE, Espíndola e Silva (1997), expõem que,

\begin{abstract}
[...] no campo das pesquisas em geografia que se apoiam nessa categoria, é lamentável constatar que boa parte de trabalhos fomenta uma espaciologia estéril, pois se ocupa dos processos históricos, sociais e geográficos, sem partir da esfera da produção - prática absolutamente crucial na análise das sociedades onde o capitalismo é dominante (ESPÍNDOLA; SILVA, 1997, p. 62).
\end{abstract}

Deste modo, concorda-se com os autores supracitados, pois os estudos sobre redes urbanas não devem e não podem partir de outra esfera que não seja a da produção e, isso contempla os alicerces de nossa proposta, fundamentada na FSE. Assim, credita-se ao setor produtivo a peça fundamental para se iniciar a análise de qualquer rede urbana, pois vivemos numa sociedade capitalista, onde os centros urbanos e por consequência as redes urbanas são estruturadas pela acumulação de capital, através de seus complexos de produção, distribuição, circulação e consumo. Valendo enfatizar que, "[...] não apenas a relação de uma nação com outras, porém até mesmo toda a estrutura interna dessa nação, depende do nível de desenvolvimento de sua produção e de seu intercâmbio interno e externo" (MARX; ENGELS, 2007, p. 43). Assim, a partir da análise da produção, edificada no método materialista pode-se explicar teoricamente as relações tanto interurbanas, como intraurbanas entre os lugares.

\title{
3. RESULTADOS E DISCUSSÕES
}

\subsection{Algumas discussões sobre o conceito de rede urbana}

A inserção dos estudos sobre rede urbana no Brasil tem sua gênese a partir da publicação do artigo de Deffontaines (1944 e 1945) "Como se constituiu no Brasil a rede das cidades", no Boletim de Geografia. Neste artigo,

\footnotetext{
${ }^{2}$ A primeira versão deste artigo foi publicado no Bulletin de la Societé de Géographie de Lille (France), a. 59, tomo 82, n. 9, 1938. No Brasil foi publicado no Boletim Geográfico, em duas partes, a primeira em 1944 e a segunda em 1945:
} 
Deffontaines (1944; 1945) assinala o estado da arte do sistema urbano brasileiro das décadas de 1930-1940, assegurando que a rede urbana brasileira se encontrava em sua "infância", marcada pela expectativa de crescimento e instabilidade das cidades.

Em 1956, durante o Congresso da União Geográfica Internacional (UGI), realizado no Rio de Janeiro, a temática da rede urbana aparece novamente e, a partir de então, vários pesquisadores realizaram análises sobre o tema.

As pesquisas desenvolvidas sobre a temática da rede urbana voltaram a receber maior dedicação, a partir da década de 1990. Podemos dizer que, até mesmo, durante toda a primeira década do século XXI, foram levados adiante estudos sobre a temática que ainda proclamam da "teoria das localidades centrais" proposta pelo Geógrafo Alemão Walter Christaller, como a mais adequada teoria para problematizar uma dada rede urbana, ganham destaque, por exemplo, o estudo do IBGE (2008), entre outros.

A rede urbana é estruturada a partir da união de centros urbanos articulados entre si, o que por sua vez, demonstra e condiciona as transformações econômico-sociais (CORRÊA, 1988). O importante é compreender que para desvendar uma dada rede urbana, a análise de sua gênese e dinâmica se torna imprescindível e, deve ser buscada em seu processo histórico, atribuindo a rede uma natureza social, tornando-a uma dimensão sócio-espacial, que reflete e condiciona a sociedade que a produziu. Deste modo, a rede urbana seria "[...] um produto social, historicamente contextualizado, cujo papel crucial é o de, através de interações sociais espacializadas, articular toda a sociedade numa dada porção do espaço, garantindo a sua existência e reprodução" (CORRÊA, 1997, p.93).

Sendo a rede urbana uma dimensão sócio-espacial da sociedade, constatamos que os processos de concepção, apropriação e circulação do valor excedente, frequentemente modificado, já que é integrado a divisão territorial do trabalho, estão igualmente em constante alteração. O que, todavia nos faz entender que a rede urbana é um reflexo "[...] dos efeitos acumulados da prática de diferentes agentes sociais, sobretudo as grandes corporações multifuncionais e multilocalizadas que, efetivamente, introduzem, tanto na 
cidade como no campo, atividades que geram diferenciações entre os centros urbanos [...]". Tais, diferenciações sócio-espaciais, provocam alterações dialéticas, através de continuidades e descontinuidades. "[...] Neste sentido, é necessário que se compreenda a lógica da implantação das atividades no mais ou menos complexo mosaico de centros e hinterlândias [...]". Isso recomenda ponderarmos às "[...] motivações dos diversos agentes sociais, bem como o entendimento dos conflitos de interesses entre eles [...]. Implica, ainda, colocar em evidência as práticas que viabilizaram a articulação entre os distintos centros urbanos e suas hinterlândias [...]" (CORRÊA, 2006, p. 27).

A rede urbana é ainda condição para a divisão territorial do trabalho, pois define os pontos de relações e as vias de tráfego por onde os fluxos são postos e permitem a concepção e transformação constante e desigual de atividades e cidades (FRESCA, 2004). Assim, a rede urbana, através dos papéis de seus centros urbanos, articula: setor primário, setor secundário, setor financeiro, comércio atacadista e varejista, serviços de armazenagem, transporte, administrativo, contábil, educação, saúde dentre outros. Portanto, são nos centros inseridos em uma determinada rede urbana, que se produzem as condições imperativas para a produção, distribuição, circulação e consumo.

A rede urbana brasileira era até o início dos anos 1950 assinalada por um grau limitado de diversificação funcional de suas cidades, como Deffontaines (1945) mencionou, a rede urbana brasileira se encontrava em sua "infância", ou seja, seu processo de formação havia tão somente iniciado. Sua importância relacionava-se a posição que ocupava na hierarquia urbana, vinculada a divisão territorial do trabalho revelada, segundo suas funções centrais distribuídas conforme o modelo hierárquico christalleriano.

Este modelo hierárquico supracitado foi estruturado pelo geógrafo alemão Walter Christaller, nomeando-se "teoria das localidades centrais"3. Nele, Christaller (1966) demonstrou a presença de uma hierarquia entre cidades determinadas pela lógica da extração tributária e pelas necessidades da circulação mercantil estabelecidas permanentemente no território. Nesta

\footnotetext{
${ }^{3}$ Sobre lugar central, Christaller (1966) menciona que a principal função ou característica de uma cidade, é a de ser o centro de uma região. Os locais que são centros de regiões o autor denominou de lugares centrais.
} 
teoria, qualquer estabelecimento comercial, industrial ou prestador de serviços, fornece bens e serviços a uma região próxima do centro fornecedor, representando, assim, uma polarização espacial da aglomeração urbana. Proporcionando, a constituição de uma hierarquia de cidades, em que, no nível mais elementar, estariam as cidades produtoras basicamente de bens e serviços, aqueles mais procurados pela população para sua reprodução social cotidiana, e, do outro lado, estariam os centros maiores, geradores de produtos e serviços mais especializados para uma área territorial mais extensa.

A característica básica da teoria das localidades centrais, não é mais válida ${ }^{4}$ para Santos (1993, p.53), pois a rede urbana torna-se "Cada vez mais diferenciada, cada vez mais complexificada, cada cidade e seu campo respondem por relações específicas, próprias às condições novas da realização da vida econômica e social [...] Hoje, cada cidade é diferente da outra, não importa seu tamanho [...]". Essa nova característica da rede urbana, a de ser complexa e diferenciada se expressa, principalmente pelas diversas maneiras como ocorrem suas inserções na divisão territorial do trabalho, que podem ser por uma, ou várias produções propriamente ditas. Pois, cada rede e centro urbano se inserem distintamente nos processos de produção, distribuição, circulação e consumo, mesmo porque, no sistema capitalista de produção os centros melhores situados tendem a se sobressair, visto que, o que interessa é a redução de custos e sobrevalorização de lucros, onde a cada nova atividade surge modelos de localização particulares que buscam atender à lógica do capital.

O parágrafo anterior explica que a posição de um centro na hierarquia urbana não é mais suficiente para entender sua importância. Recentemente, necessita-se considerar "[...] suas especializações funcionais, sejam industriais ou vinculadas aos serviços [...]" porque a "[...] divisão territorial do trabalho entre os centros urbanos amplia-se". A complexidade funcional oriunda desta nova fase do desenvolvimento econômico-social se traduz no fato de um centro

\footnotetext{
4 Para nós a teoria ainda é valida, pois como o próprio Christaller (1966) mencionou o esquema matemático rígido pode e deve ser modificado sempre que se considerar necessário, sobretudo, para buscar aproximar o esquema de uma determinada realidade. Assim, o que devemos fazer é aprofundar a teoria acompanhando o desenvolvimento da sociedade que é mutável.
} 
situar-se em pelo menos duas redes. A primeira constituída por localidades centrais, na qual, cada centro tem na rede urbana uma posição vinculada à distribuição de bens e serviços "[...] (metrópole, capital regional, centro subregional, centro de zona, centro local) [...]"; a segunda, menos desenvolvida e mais irregular, em que cada centro "[...] desempenha um papel singular e/ou complementar a outros centros" (CORRÊA, 1997, p.100).

Assim, cada centro pode ter relações com centros de níveis hierárquicos mais elevados, não necessariamente sendo um centro do próximo nível hierárquico, as relações podem ser realizadas de um centro local diretamente com a metrópole nacional. Destacando que, o modelo teórico básico não se alterou, o que se alterou foram as múltiplas determinações de suas relações. Diante disso, para nós a rede urbana brasileira pode ser analisada através da teoria Christalleriana, basta fazermos os complementos necessários para acompanhar a complexificação atual da sociedade e rede urbana, visto que a complexidade da divisão territorial do trabalho leva a numerosas especializações funcionais/produtivas, que definem diversos centros urbanos.

\subsection{A inserção de Ampére - Paraná na rede urbana de Francisco Beltrão - Paraná}

Conforme o estudo, denominado de Regiões de Influência das Cidades (REGIC) publicado em 2008 pelo IBGE e, no que diz respeito aos seus resultados obtidos, verificou-se que, o mesmo subdivide as sedes municipais brasileiras em sete níveis hierárquicos: Grande Metrópole Nacional, representado por São Paulo; Metrópole Nacional (Rio de Janeiro); Metrópole (Brasília). As Capitais Regionais integram 70 cidades, "[...] Com capacidade de gestão no nível imediatamente inferior ao das metrópoles, têm área de influência de âmbito regional, sendo referidas como destino, para um conjunto de atividades, por grande número de municípios. [...]" (IBGE, 2008, p. 11), estas Capitais Regionais se dividem em três categorias: a) 11 centros urbanos, b) 20 cidades e, c) 39 cidades. Na sequência aparecem os Centros Sub- 


\section{A INSERÇÃO DA CIDADE PEQUENA DE AMPÉRE - PR NA REDE URBANA A PARTIR DA DINÂMICA INDUSTRIAL}

Regionais que agregam 169 cidades, subdivididas em duas categorias: a) 85 cidades e b) 79 cidades; Os Centros de Zona, são formados por 556 cidades e, também se dividem em duas categorias a) 192 cidades e b) 364 cidades, estes possuem atuação restrita à sua área imediata, além de exercerem funções de gestão incipientes. E, por fim, aparecem os Centros Locais constituídos por 4.473 cidades formados por, predominantemente, menos de 10 mil habitantes que servem apenas às necessidades básicas de sua população (IBGE, 2008).

Vale destacar que, o IBGE pesquisou 4.625 cidades de um universo de 5.564 sedes municipais vigentes em 2007, das quais aproximadamente $85 \%$ possuíam menos de 20.000 habitantes.

A seguir, apresenta-se o quadro 1 , onde sintetiza-se a atual rede de cidades, com seus níveis hierárquicos e destaca-se os centros paranaenses.

Esta breve apresentação dos resultados do REGIC (IBGE, 2008) em relação à rede urbana nacional e paranaense, vem ao encontro de possibilitar ao leitor um melhor entendimento e nos permite situar este trabalho sobre a inserção da cidade de Ampére na rede urbana.

\begin{tabular}{|c|c|c|c|}
\hline Níveis hierárquicos & $\begin{array}{l}\text { Total de } \\
\text { Cidades }\end{array}$ & $\begin{array}{c}\text { Total de } \\
\text { Cidades PR }\end{array}$ & Cidades Paranaenses \\
\hline a) Grande Metrópole Nacional & $01-\mathrm{SP}$ & -- & -- \\
\hline b) Metrópole Nacional & $\begin{array}{l}02-\mathrm{RJ}- \\
\text { Brasília }\end{array}$ & -- & -- \\
\hline c) Metrópole & 09 & 01 & Curitiba \\
\hline Capital Regional 'a' & 11 & -- & -- \\
\hline Capital Regional 'b' & 20 & 03 & Cascavel, Londrina e Maringá. \\
\hline Capital Regional 'c' & 39 & 01 & Ponta Grossa \\
\hline Centro Sub-Regional 'a' & 85 & 10 & $\begin{array}{l}\text { Apucarana, Campo Mourão, Foz do } \\
\text { lguaçu, } \quad \text { Francisco } \quad \text { Beltrão, } \\
\text { Guarapuava, Paranaguá, Paranavaí, } \\
\text { Pato Branco, Toledo e Umuarama. }\end{array}$ \\
\hline Centro Sub-Regional 'b' & 79 & 04 & $\begin{array}{l}\text { Cianorte, Ivaiporã, Santo Antônio da } \\
\text { Plantina e União da Vitória. }\end{array}$ \\
\hline Centro de Zona 'a' & 192 & 17 & $\begin{array}{l}\text { Arapongas, Assis Chateaubriand, } \\
\text { Bandeirantes, Cornélio Procópio, } \\
\text { Dois Vizinhos, Ibaiti, Irati, } \\
\text { Jacarezinho, Jandaia do Sul, } \\
\text { Laranjeiras do sul, Loanda, Marechal } \\
\text { Cândido Rondon, Medianeira, } \\
\text { Palmas, Telêmaco Borba. }\end{array}$ \\
\hline Centro de Zona 'b' & 364 & 23 & $\begin{array}{l}\text { Andirá, Barracão, Campina da Lagoa, } \\
\text { Capanema, Chopinzinho, Coronel } \\
\text { Vivida, Faxinal, Goioerê, Guaíra, }\end{array}$ \\
\hline
\end{tabular}




\begin{tabular}{|c|c|c|c|}
\hline & & & $\begin{array}{l}\text { Jaguariaíva, Matinhos, Nova } \\
\text { Londrina, Palmeira, Paranacity, } \\
\text { Pitanga, Prudentópolis, Quedas do } \\
\text { Iguaçu, Rio negro, Roncador, São } \\
\text { José do Ivaí, São Mateus do Sul, } \\
\text { Siqueira Campos, Venceslau Brás. }\end{array}$ \\
\hline Centro Local & 4.773 & 344 & $\begin{array}{l}\text { Dentre elas destacamos: Ampére, } \\
\text { Antonia, Bituruna, Candoí, Capitão } \\
\text { Leônidas Marques, Castro, Mas, Itapejara } \\
\text { Clevelândia, Corbélia, Itaí, Jaguapitã, Jataizinho, } \\
\text { d'Oeste, Ivaí, } \\
\text { Mariópolis, Marmeleiro, Matelândia, } \\
\text { Nova Prata do Iguaçu, Palotina, } \\
\text { Realeza, Renascença, Santo Antônio } \\
\text { do Sudoeste, São João, São Jorge } \\
\text { d'Oeste, Verê, Vitorino. }\end{array}$ \\
\hline
\end{tabular}

Quadro 1. Síntese do REGIC, com Níveis Hierárquicos dos centros urbanos do PR. Fonte: IBGE, 2008, p.66-69.

A atual rede urbana de Francisco Beltrão (IBGE, 2008), é formada pela cidade de Francisco Beltrão mais 24 centros e, é polarizada por Cascavel (o mapa 1, apresenta a rede de Francisco Beltrão e a rede de Pato Branco). Francisco Beltrão e Dois Vizinhos possuem o maior percentual de população urbana, 85,43\% e 77,67\%, respectivamente (IBGE, 2010), o maior número de atividades e os maiores níveis hierárquicos (Francisco Beltrão, "Centro Subregional A" e Dois Vizinhos, "Centro de Zona A"). Ampére aparece na rede como "Centro Local" (IBGE, 2008). 
CASARIL, C. C.

A INSERÇÃO DA CIDADE PEQUENA DE AMPÉRE - PR NA REDE URBANA A PARTIR DA DINÂMICA INDUSTRIAL

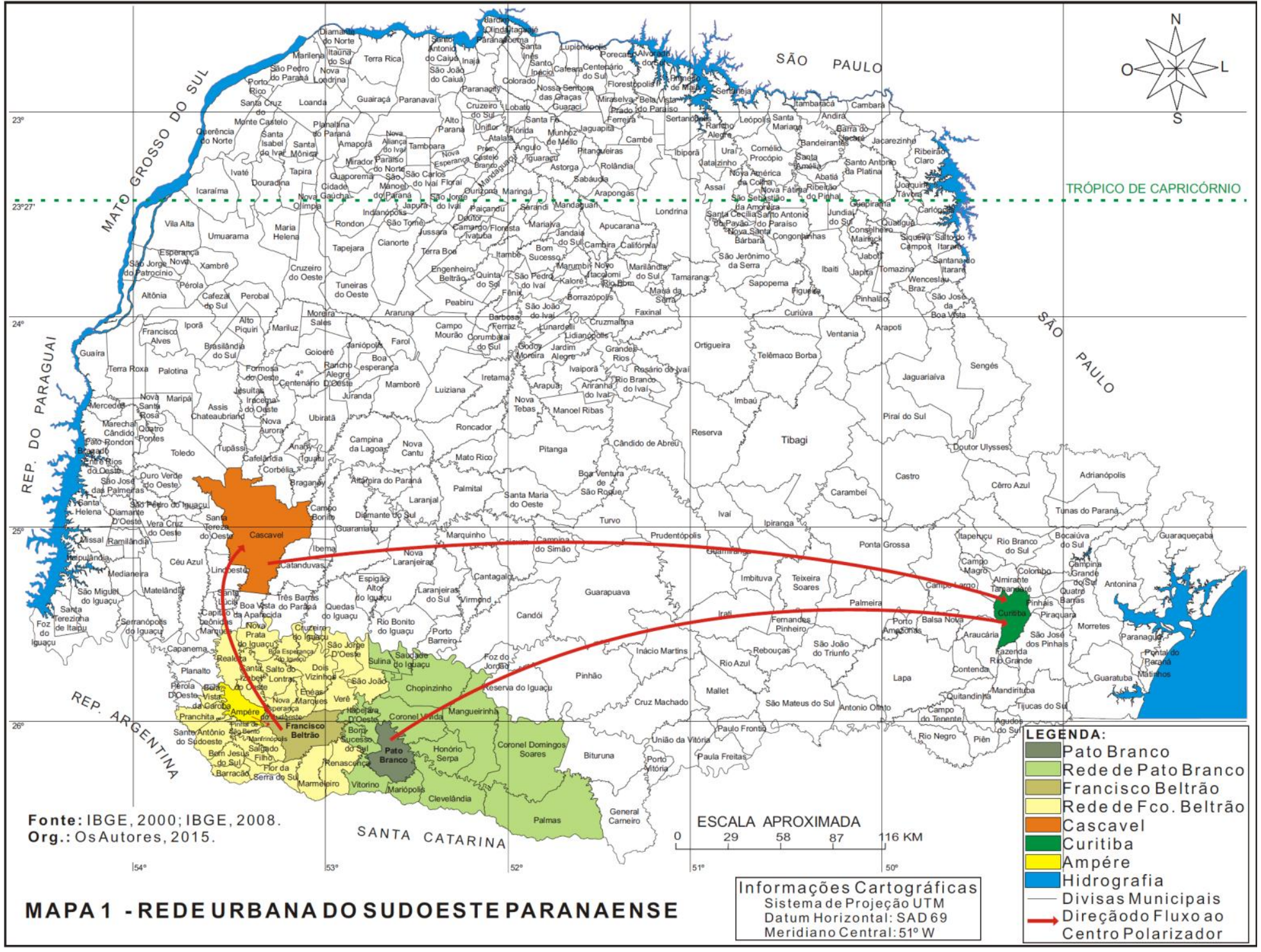

R. Ra'e Ga - Curitiba, v. 37, p.227 - 254 , Ago/2016 
O mapa 1, apresenta duas redes urbanas. A fim de um melhor entendimento, apresenta-se a figura 1, que destaca a estrutura da rede urbana de Francisco Beltrão, formada a partir do REGIC (IBGE, 2008). Ressaltando que, uma figura neste mesmo estilo é formada para apresentar a rede de Pato Branco, porém como este trabalho discute a inserção da cidade pequena de Ampére $(P R)$ na rede urbana e, como esta cidade faz parte da região de influência de Francisco Beltrão, apresenta-se apenas uma figura. Todavia, no mapa 1, deixa-se claro que na mesorregião Sudoeste Paranaense existem duas redes urbanas (IBGE, 2008).

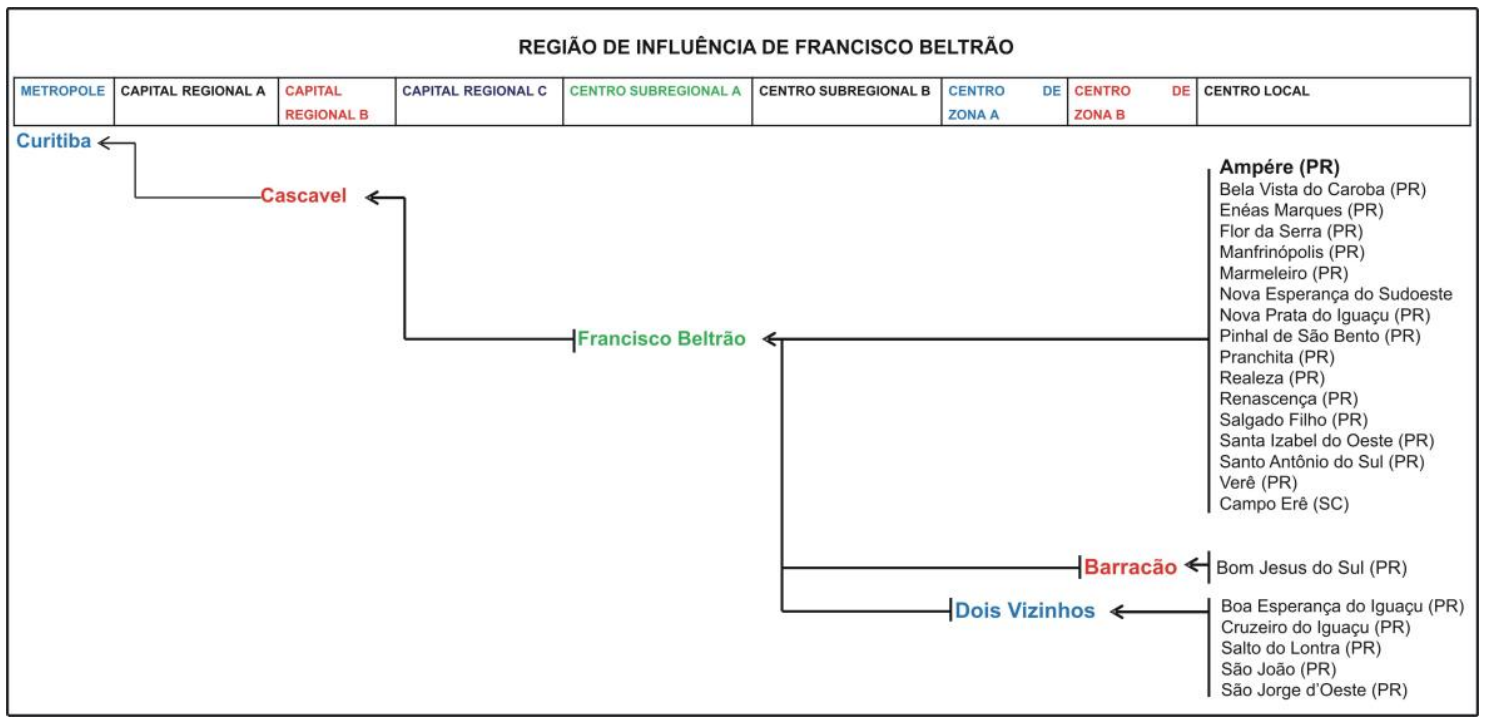

Figura 1. Rede Urbana de Francisco Beltrão - PR.

Fonte: IBGE, 2008. Org.: CASARIL, 2014, p. 294.

Os centros urbanos da rede desenvolveram uma urbanização reduzida, pois seu patamar era de apenas 16\%, em 1970 e evoluiu para 67,42\% em 2010. Uma taxa de urbanização menor que a nacional $(84,4 \%)$, menor que a do Estado (85\%), menor que a do Sudoeste Paranaense $(70,23 \%)$ e menor que a da rede de Pato Branco (76,78\%). Um fato que corrobora para que a rede possua um baixo índice de urbanização é que, dos 25 centros da rede, nove possuem maior porcentagem de população rural e seis possuem população rural na faixa dos 40\% (IBGE, 2010). A tabela 1 abaixo apresenta os dados demográficos da Rede Urbana de Francisco Beltrão. 


\section{A INSERÇÃO DA CIDADE PEQUENA DE AMPÉRE - PR NA REDE URBANA A PARTIR DA DINÂMICA INDUSTRIAL}

Tabela 1 - População da Rede Urbana de Francisco Beltrão (IBGE 2010)

\begin{tabular}{lccccc}
\hline \multicolumn{1}{c}{ MUNICíPIO } & \multicolumn{5}{c}{ POPULAÇÃO } \\
& TOTAL & URBANA & \% & RURAL & $\%$ \\
\hline Francisco Beltrão & $\mathbf{7 8 . 9 5 7}$ & $\mathbf{6 7 . 4 5 6}$ & $\mathbf{8 5 , 4 3}$ & $\mathbf{1 1 . 5 0 1}$ & $\mathbf{1 4 , 5 7}$ \\
Ampére & 17.308 & 13.257 & 76,59 & 4.051 & 23,41 \\
Barracão & 9.737 & 7.015 & 72,04 & 2.722 & 27,96 \\
Bela Vista da Caroba & 3.939 & 1.038 & 26,35 & 2.901 & 73,65 \\
Boa Esperança do Iguaçu & 2.768 & 957 & 34,57 & 1.811 & 65,43 \\
Bom Jesus do Sul & 3.796 & 933 & 24,58 & 2.863 & 75,42 \\
Cruzeiro do Iguaçu & 4.274 & 2.619 & 61,28 & 1.655 & 38,72 \\
Dois Vizinhos & 36.198 & 28.115 & 77,67 & 8.083 & 22,33 \\
Enéas Marques & 6.101 & 2.126 & 34,85 & 3.975 & 65,15 \\
Flor da Serra do Sul & 4.725 & 1.644 & 34,79 & 3.081 & 65,21 \\
Manfrinópolis & 3.127 & 652 & 20,85 & 2.475 & 79,15 \\
Marmeleiro & 13.909 & 8.835 & 63,52 & 5.074 & 36,48 \\
Nova Esperança do Sudoeste & 5.110 & 1.753 & 34,31 & 3.357 & 65,69 \\
Nova Prata do Iguaçu & 10.369 & 6.066 & 58,50 & 4.303 & 41,50 \\
Pinhal de São Bento & 2.620 & 1.162 & 44,35 & 1.458 & 55,65 \\
Pranchita & 5.632 & 3.609 & 64,08 & 2.023 & 35,92 \\
Realeza & 16.348 & 11.808 & 72,23 & 4.540 & 27,77 \\
Renascença & 6.810 & 3.483 & 51,15 & 3.327 & 48,85 \\
Salgado Filho & 4.403 & 2.252 & 51,15 & 2.151 & 48,85 \\
Salto do Lontra & 13.672 & 7.429 & 54,34 & 6.243 & 45,66 \\
Santa Izabel do Oeste & 13.134 & 7.427 & 56,55 & 5.707 & 43,45 \\
Santo Antônio do Sudoeste & 18.905 & 13.712 & 72,53 & 5.193 & 27,47 \\
São João & 10.607 & 6.746 & 63,60 & 3.861 & 36,40 \\
São Jorge D'Oeste & 9.085 & 5.214 & 57,39 & 3.871 & 42,61 \\
Verêt & 7.879 & 3.284 & 41,68 & 4.595 & 58,32 \\
\hline TOTAL REDE Francisco Beltrão & $\mathbf{3 0 9 . 4 1 3}$ & $\mathbf{2 0 8 . 5 9 2}$ & $\mathbf{6 7 , 4 2}$ & $\mathbf{1 0 0 . 8 2 1}$ & $\mathbf{3 2 , 5 8}$ \\
\hline TOTAL REDE Pato Branco & 239.148 & 183.626 & 76,78 & 55.522 & 23,22 \\
\hline TOTAL SUDOESTE do PR & 587.505 & 412.624 & 70,23 & 174.881 & 29,77 \\
\hline TOTAL PARANÁ & 10.444 .526 & 8.912 .692 & 85,33 & 1.531 .834 & 14,67 \\
\hline Fonte: IBGE, 2008; 2010. & & & & & \\
Org.: CASARIL, 2014. & & & & & \\
& & & & &
\end{tabular}

Nenhum centro da rede possuía população urbana superior a 50\% em 1970 e, em 1980, apenas Francisco Beltrão alcançara este índice (58,43\%). Já em 2010, 16 centros ultrapassaram os 50\% de urbanização (Ampére 76,59\%), ou seja, somente $64 \%$ dos centros da rede eram urbanos.

Pode-se considerar a maioria dos centros da rede de Francisco Beltrão como cidades locais, aqueles que estão na confluência do rural com o urbano (CORRÊA, 1999), sendo uma tarefa árdua diferenciá-los. Mas pode-se dizer que, os dois principais centros da rede, Francisco Beltrão e Dois Vizinhos, são cidades pequenas, o mesmo valendo para Ampére. Francisco Beltrão apresenta-se em nível superior, devido à sua dinâmica, podemos até considerá-la como estando no limiar entre a cidade pequena, propriamente dita 
e a cidade de porte médio, mas que, sobretudo, trata-se de uma cidade regional, pois possui uma capacidade de organização e direção da vida regional. Vale relativizar que, Francisco Beltrão se enquadra na rede urbana nacional como um "Centro Sub-Regional A", porém seu enquadramento alterase quando se analisa este centro urbano e sua rede no Estado do Paraná, pois se apresenta com uma dinâmica muito mais ampla, sobretudo, quando se analisa seu papel no Sudoeste Paranaense, neste último o papel/função de Francisco Beltrão pode ser considerado como uma cidade média, mas, sobretudo, uma cidade que possui características de comandar e gerir a região. Por isso, alguns chegam a relativizar e denominar Francisco Beltrão e Pato Branco como duas capitais de uma única região (o que seria uma anomalia urbana).

Os centros urbanos de Realeza, Santo Antônio do Sudoeste, Ampére e São João, por possuírem uma dinâmica demográfica e de atividades urbanas em expansão, podem ser considerados também, como cidades pequenas, sobretudo, os três últimos centros, que possuem dinâmicas industriais consideradas e é através destas produções que se inserem na rede (FRESCA, 2001).

Já os centros urbanos de menores níveis hierárquicos da rede, ou seja, as cidades locais podem ser sintetizadas pelas palavras de José Sidnei Gonçalves (2001) "o comércio local e toda estrutura de serviços urbanos [...], giram em torno do movimento das suas lavouras e criações, sendo que, em anos de safra boa, há um nítido ânimo da vida local, caso contrário, cria-se um clima de dificuldades" (GONÇALVES, 2001, p.55). Aqui, não se pode esquecerse de mencionar que, algumas cidades locais da rede vêm apresentando um importante processo de industrialização, o que por sua vez, contribui para ampliar a dinâmica urbana e, em alguns casos alterar qualitativamente a análise realizada pelo autor supracitado.

Como este trabalho analisa determinadas indústrias instaladas em Ampére, neste momento se faz necessário apresentar o quadro 2, que nomeia as indústrias analisadas e seus respectivos anos de fundação. Em sequência procede a apresentação de informações de cada empresa industrial e realiza- 


\section{A INSERÇÃO DA CIDADE PEQUENA DE AMPÉRE - PR NA REDE URBANA A PARTIR DA DINÂMICA INDUSTRIAL}

se análise comparativa, possibilitando um entendimento de como a dinâmica do setor industrial contribuiu para a complexidade da rede urbana de Francisco Beltrão e possibilitou a Ampére, uma cidade local, inserir-se em mais de uma rede urbana.

\begin{tabular}{|l|c|}
\hline \multicolumn{1}{|c|}{ Indústria } & Gênese \\
\hline Krindges e Filhos Ltda. & 1977 \\
\hline Aicone & 1989 \\
\hline Indústria de Pias GhelPlus Ltda. & 1990 \\
\hline Indústria de Móveis Simosul Ltda. & 1990 \\
\hline GAAM Indústria e Comércio de Móveis Ltda. & 1995 \\
\hline Indústria de Móveis Notável & 1996 \\
\hline Krindges Industrial Ltda. (fusão entre Krindges e Filhos Ltda. e Aicone) & 1998 \\
\hline Grilazer Espetos e Grelhas & 1999 \\
\hline
\end{tabular}

Quadro 2. Lista de indústrias analisadas de Ampére e suas gêneses Fonte: CASARIL, 2014.

Dando destaque a Ampére, em relação ao setor de confecções, verificase que o mesmo começou a sair do complexo rural, no decorrer da década de $1970^{5}$. Conforme informações obtidas em trabalho de campo (entrevista aberta), realizada com o Sr. Luiz Krindges (diretor da indústria), a indústria Krindges de Ampére teve sua gênese em 1977, quando Dona Ilária, que costurava roupas masculinas sob medida percebeu um potencial para industrializar a produção, pois já recebia ajuda do marido e de seus filhos. A partir disso, e com um capital acumulado do próprio trabalho, dona llária funda em novembro de 1977 a "Krindges e Filhos Ltda.", inicialmente a produção de calças sociais era toda comercializada em seu próprio comércio, a "Loja Leoni". Em 1982, os irmãos estimulados por aumentar a produção familiar, contratam 20 funcionários e passaram a produzir produtos em série (3.500 peças/mês) entre calças e bermudas, destinadas à loja da família e às lojas e atacados da região. Pelas informações concedidas, a produção na década de 1980, ficou restrita "comercialmente" a região e a algumas cidades do Oeste de SC. Foi somente no decorrer dos anos $1990^{6}$ que os produtos passaram a serem

\footnotetext{
${ }^{5}$ Aqui vale destacar que, todas as informações referentes às indústrias que seguem foram obtidas a partir de trabalhos de campos, onde foram realizadas entrevistas semiestruturadas com diretores das indústrias e/ou responsáveis pelo setor administrativo. Para maiores detalhes sobre o processo de industrialização do Sudoeste Paranaense e da rede urbana de Francisco Beltrão, consultar Flores (2009) e Casaril (2014). ${ }^{6}$ Em 1998 a empresa já mantinha mais de 700 funcionários e por estratégias de comerciais modificaram sua razão social para Krindges Industrial Ltda., mantendo "Krindges" como nome fantasia.
} 


\section{A INSERÇÃO DA CIDADE PEQUENA DE AMPÉRE - PR NA REDE URBANA A PARTIR DA DINÂMICA INDUSTRIAL}

distribuídos para outras regiões, principalmente para cidades da região Sul e São Paulo.

Para se ter noção do desempenho industrial na rede durante os anos 1980, podemos destacar que nos dois primeiros quartéis desta década, somente três centros aumentaram o número de pessoas ocupadas. Centros estes que correspondem até hoje aos mais dinâmicos da rede, sendo eles, Francisco Beltrão, Dois Vizinhos e Ampére, onde o primeiro centro somou 460 novos postos de trabalho, o segundo gerou 586 novos empregos e Ampére apresentou um saldo positivo de 50 novas vagas. E, em relação aos estabelecimentos, ocorreu diminuição em todos os 14 centros da rede (BRASIL, 1985).

Ampére ampliou seu número de vagas de empregos industriais, entre os anos 1990 e 2000, passando de 22 estabelecimentos e 400 empregos em 1990, para 36 estabelecimentos e 1041 postos de trabalho em 1995 e a expansão continuou, até atingir a cifra de 50 unidades fabris e 1974 empregos no ano 2000 (BRASIL, 1990, 1995, 2000).

Ampére $^{7}$ despontou nesse período, pela força do empresariado local, que a partir de empréstimos, poupança familiar, entre outros, investiu no setor produtivo, com destaque para o segmento moveleiro e de confecções. Entre outras empresas, nascidas na década de 1990, nesse centro urbano, destacam-se a GhelPlus Inox, fundada em 15 de julho de 1990, produzindo inicialmente pias de aço de inox e alumínio. Atualmente, a empresa possui máquinas com tecnologia de ponta.

A empresa GhelPlus montou no final dos anos 1990, uma frota própria de caminhões, para realizar suas entregas. Nesse período, a empresa comercializava seus produtos para centros urbanos da região Sul e do Estado de São Paulo.

\footnotetext{
7 Segundo informações obtidas em trabalho de campo, verificou-se que, nos anos 1990, a Krindges era outra empresa de Ampére que possuía forte dinâmica, até porque, foi a partir dessa década que a empresa iniciou o processo de exportações de seus produtos, sobretudo para países da América do Sul. Destacando que, em 1989, o Sr. Jorge Krindges e seu sogro Alci Honório Fistarol, fundaram a indústria "Aicone" que, iniciou com 15 operários e com uma produção de roupas masculinas de 3.000 peças por mês. Em 1998, estas duas empresas a Aicone (455 funcionários) e a Krindges (645 funcionários) realizaram a fusão das mesmas, visando aumentar a competitividade, modificando assim, sua razão social para Krindges Industrial Ltda.
} 
Outra indústria instalada em Ampére nos anos 1990 foi a GAAM Indústria e Comércio de Móveis Ltda. e, a partir de informações obtidas em trabalho de campo, verificou-se que a mesma foi fundada em 1995. A empresa produz gabinetes, pias, cubas e balcões para cozinhas. Já, no final dos anos 1990, a empresa adquiriu sua frota de caminhões para realizar entregas próprias e para manter um cuidado maior com os produtos em seus deslocamentos, que empresas terceirizadas, não realizavam. Durante esta década, a empresa comercializava seus produtos, principalmente para as regiões Sul, Sudeste e Centro-Oeste, sempre através de representantes comerciais.

Outra empresa do setor moveleiro instalada em Ampére em 1990, e que contribuiu para que este centro ampliasse seus empregos produtivos, foi a Indústria de Móveis Simosul Ltda., que segundo o diretor-geral e proprietário Ivan Simonetto, iniciou produzindo móveis populares e comercializando com centros da região Sul e São Paulo. E, a partir do ano 2000, passou a produzir móveis planejados, criando assim, a marca Simonetto Design, ampliando sua área de comercialização em lojas multimarcas e, em 2010 inaugurou sua primeira loja exclusiva em Francisco Beltrão.

Outra indústria de grande dinamismo atualmente, e que não podemos nos esquecer de mencionar é a Indústria de Móveis Notável Ltda., que iniciou suas atividades, em 1996. Esta, entre outras, foram responsáveis por fazer, com que, este centro urbano tenha ampliado o número de seus estabelecimentos e empregos produtivos, sempre a partir de capital local, o que demonstra a força desses empreendedores.

A Indústria de Móveis Notável iniciou suas atividades com a produção de racks e estantes em laminado de madeira, contando com apenas cinco funcionários e com capacidade para produzir 150 peças por mês. E, até 2003, a empresa atuava somente no mercado nacional, sobretudo nos centros urbanos da região Sul e dos Estados de São Paulo, Minas Gerais e Mato Grosso do Sul, onde sua comercialização se dava a partir de representantes comerciais. 
Os centros da rede urbana de Francisco Beltrão contabilizavam em 1990, um total de 417 estabelecimentos industriais (com destaque para 0 segmento da Madeira e mobiliário com 28,78\%; Têxtil com 15,35\% e Construção civil $15,11 \%$ ) e, em 2000, o número desses estabelecimentos saltaram, para 860 unidades industriais (com ênfase para os segmentos da Construção civil, 23,72\%; Madeira e mobiliário, 20,81\%; Têxtil, 14,07\% e Alimentos e bebidas, 13,14\%). Em 2010, os estabelecimentos totalizavam 1.562 unidades industriais (Construção civil, 32,97\%; Têxtil, 15,30\%; Metalúrgica-alumínios, 11,40\%; Madeira e mobiliário, 11,01\% e Alimentos e bebidas 10,88\%) (BRASIL, 1990, 2000, 2010).

Em 1990, o setor industrial gerou 7.456 empregos na rede (destacandose os segmentos, Alimentos e bebidas, com 48,94\%; Madeira e mobiliário, 27,28\% e Têxtil, 9,54\%) e, em 2000, esse setor gerou 11.783 empregos produtivos na rede (sobretudo, para os setores de Alimentos e bebidas, com 34,73\%; Têxtil, com 26,19\% e Madeira e mobiliário, 16,19\%). Já, em 2010 os empregos industriais na rede saltaram para 25.862 (Alimentos e bebidas, 32,27\%; Têxtil, 29,79\% e Madeira e mobiliário, 10,44\%) (BRASIL, 1990, 2000, 2010).

A maior concentração de empregos industriais na rede estava nos centros de Francisco Beltrão, Dois Vizinhos e Ampére, sobretudo, por possuírem empresas de maior porte, como por exemplo, no primeiro centro, Sadia, Camilotti Camidoor, Raffer, Marel, Flessak, Gralha Azul entre outras, no segundo centro, encontrava-se em especial a Sadia, Latreille Jeans e a Pluma Agro Avícola e, em Ampére, achava-se a Krindges, Notável, Gaam e a GhelPlus.

Ampére, no ano de 1990, possuía 400 empregos industriais (sobretudo, no segmento Têxtil, com 87,50\%; Madeira e mobiliário, 10,50\%) e, em 2000, os empregos aumentaram para 1974 ocupações industriais (Têxtil, 67,93\% e Madeira e mobiliário, 19,81\%, assim, podemos verificar que este último setor ampliou a geração de empregos em relação ao setor de confecções, ou seja, as indústrias moveleiras começam a ganhar destaque nessa década em Ampére). Já, em 2010, as ocupações do setor industrial saltaram para 2.860 
empregos (Têxtil, 53,00\% e Madeira e mobiliário, 27,13\%, ou seja, o setor moveleiro continuou ampliando a geração de empregos) (BRASIL, 1990, 2000, 2010).

Francisco Beltrão, Dois Vizinhos e Ampére, são responsáveis por gerarem 6252, ou 83,85\% dos empregos industriais em 1990 e, 8234, ou $69,88 \%$ dos empregos na indústria em 2000. Em 2010, geraram 16.344, ou $63,19 \%$ dos empregos. Assim, estes são os três principais centros industriais da rede. Destacando que, se incluíssemos Realeza e Santo Antônio do Sudoeste, teríamos, em 1990, 6.838, ou 91,71\% dos empregos industriais da rede, em 2000, 9.037, ou 76,70\% dos empregos e, em 2010, 18.519, ou $71,60 \%$ dos empregos da indústria da rede, o que representa uma grande concentração (BRASIL, 1990, 2000, 2010).

Ao se verificar o número de estabelecimentos e de empregos gerados por cada setor (secundário e terciário), somados aos seus respectivos PIBs, pode-se falar claramente que os centros da rede, concentram seus maiores números de empregos no setor terciário e possuem seus maiores PIBs, igualmente no setor terciário, onde somente quatro centros da rede apresentaram em 2010 seus maiores PIBs no setor agropecuário (Bom Jesus do Sul; Enéas Marques; Manfrinópolis e Nova Esperança do Sudoeste), estes apresentam funções urbanas reduzidas, capazes de satisfazer somente suas necessidades mínimas. A partir das informações, já incluídas no trabalho, verifica-se que, Francisco Beltrão, Dois Vizinhos e Ampére, possuíam fortes dinâmicas no setor industrial, onde seus PIBs e empregos industriais somavam, em Ampére, 27,09\% do PIB e 2.860, ou 65,55\% dos empregos; em Dois Vizinhos, $31,85 \%$ do PIB e 4.767, ou 47,85\% das ocupações e em Francisco Beltrão, 25,85\% do PIB e 8.717, ou 40,12\% dos empregos no setor industrial. Assim, pode-se dizer que, estes três centros possuíam fortes dinâmicas no setor produtivo e, sobretudo, Ampére tinha seu principal papel, representado pela função industrial (http://www.ipeadata.gov.br/).

Portanto, Ampére é um dos exemplos de desenvolvimento regional via industrialização, realizado após os anos 1980. Esse município que antes era dependente basicamente do setor rural, passou por uma mudança em sua 
dinâmica, onde os industriais do setor moveleiro e do vestuário passaram a instalar suas empresas e a modernizá-las, passando a produzir para atender à demanda nacional e não apenas regional, desse modo, o setor industrial gerou em 2010, 2.860 empregos (65,55\% do total de empregos). Considerando que a população total de Ampére soma 17.308 habitantes e, destes 13.257 são habitantes urbanos, pode-se verificar que $21,57 \%$ da população urbana estão ocupados no setor industrial (BRASIL, 2010; IBGE, 2010).

O setor produtivo dos centros da rede são os principais fomentadores do que Alexander (1968) denomina de renda básica, aquelas que ampliam as interações interurbanas, pois a partir destas, a rede amplia seus alcances para centros de todas as regiões brasileiras, não nos esquecendo da dinâmica proporcionada via exportações e importações de e para outros países.

Em Ampére, verificou-se que entre as empresas mais dinâmicas do setor industrial e que realizaram exportações estão a Notável, a Ghelplus, a Gaam e a Indústria de Móveis Simosul Ltda. (Nome Fantasia: Simonetto Design). Estas nasceram no decorrer dos anos 1990 e, atualmente estão entre as mais dinâmicas da rede urbana. Todas as indústrias que realizaram exportações, também concretizaram importações, onde se somam a estas, a Movelmar e a Krindges.

A Notável contava em dezembro de 2013, com 402 funcionários e produzia 85 mil peças por mês, entre racks, estantes, escrivaninhas, tábuas de passar, fruteiras e armários multiusos. Possuindo ainda, uma frota de 40 caminhões, para operação logística própria. Do total da produção, 85\% são destinadas ao mercado interno, sobretudo, para 15 Estados (Alagoas, Bahia, Goiás, Minas Gerais, Mato Grosso do Sul, Mato Grosso, Pará, Paraíba, Pernambuco, Piauí, Paraná, Rio de Janeiro, Rio Grande do Sul, Santa Catarina, Sergipe, São Paulo, Tocantins) e, desde 2004, a empresa passou a atuar no mercado externo, especialmente, nos países da América do Sul, América Central e para Angola. Em relação às importações, a China é o seu principal fornecedor, sobretudo, em relação aos derivados de aço e metal, como as corrediças, dobradiças e outros produtos derivados desta matériaprima, que permitem baratear os móveis e conquistar maior competitividade. 
A indústria de móveis Simosul Ltda. (Simonetto Design), conforme o Sr. Ivan Simonetto (diretor-geral), conta com uma unidade industrial com área construída de $14 \mathrm{mil} \mathrm{m}^{2}$, com maquinários de tecnologia avançada, com capacidade de produzir 40 mil unidades por mês de móveis fabricados com material MDP e MDF. A Simonetto produz móveis planejados, para cozinha, dormitórios, banheiros, área de serviço, closet e Home Office.

A Simonetto Design comercializa seus produtos em algumas lojas multimarcas e em lojas exclusivas (as vendas e escolhas dessas lojas multimarcas se realizam por representantes comerciais), atendendo atualmente os estados do Acre, Bahia, Espirito Santo, Mato Grosso, Paraná, Rio de Janeiro, Rio Grande do Sul, Santa Catarina, São Paulo e Sergipe. Conta também com uma loja exclusiva em Santa Rita no Paraguai.

A Simonetto realiza exportações para o Paraguai, onde possui uma loja exclusiva, mas, as maiores interações realizadas no mercado externo por esta empresa, diz respeito a importações de matérias-primas, sobretudo, da China.

Importante destacar que, o Sr. Pedro Rodrigues da Silva em sociedade com o Sr. Dair Sabedot são proprietários da empresa Ghelplus Inox (fundada em 1990) e o Sr. Pedro Rodrigues da Silva é também sócio proprietário da GAAM (instalada em 1995) e da Grilazer (fundada em 1999, uma empresa especializada na produção de espetos e grelhas para churrascos, que distribui seus produtos em todos dos Estados brasileiros).

Assim, pode-se verificar que primeiro veio a Ghelplus, produzindo pias e cubas em alumínio e inox, o que por sua vez, suscitou a instalação da GAAM, produzindo gabinetes para banheiro e balcões para cozinhas $^{8}$ (indústria acessória), para complementar a produção da Ghelplus, e logo após instalam a Grilazer, pois já trabalhavam com alumínio e inox e devido à colonização gaúcha (acostumados a fazer churrascos), formavam uma grande demanda para esse produto, servindo assim, como estímulo a instalação dessa empresa.

\footnotetext{
${ }^{8}$ Como estratégia para sair da crise durante a década de 1990, a GAAM se especializou na produção gabinetes para banheiro, retirou alguns produtos da linha de produção e diminuiu a produção dos outros produtos. Ou seja, a GAAM, apostou no crescimento da construção civil, para aumentar a demanda de seus gabinetes modernos para banheiro.
} 
A Ghelplus pesquisa e desenvolve seus produtos na unidade matriz, a empresa exporta para América Central, Europa e África. A filial em Escada PE, fabrica diversas linhas de produtos para atender às regiões Norte e Nordeste do Brasil. A empresa possui também, um Centro de Distribuição localizado na cidade de Atibaia - SP, a uma distância de $60 \mathrm{~km}$ da capital do Estado.

Outro destaque em relação à Ghelplus é que, em 2006 a empresa adquiriu a marca chamada De Bacco (móveis planejados), uma indústria com atuação apenas no sul do Brasil e, para tanto, a empresa mantém em Bento Gonçalves - RS, uma central para atender o mercado consumidor dos produtos De Bacco.

Os produtos da Ghelplus são comercializados por meio de representantes comerciais e vendidos em 145 lojas de móveis e materiais de construção distribuídos em todos os Estados, como por exemplo, as lojas Koerich, Balaroti, Telhanorte etc.

Tanto a Ghelplus como a GAAM vêm realizando muitos investimentos em tecnologia, por exemplo, a GAAM adquiriu dois robôs ( $A B B$ Robotics) para realizar pinturas de pias, cubas e tampos, tecnologia essa, importada da Suécia, contando ainda, com máquinas importadas da Itália e da Alemanha operadas por Controle Numérico Computadorizado (CNC), com centros para furação, frisagem e corte, além de pintura UV. Vale ressaltar que, esta empresa importa esporadicamente pias e cubas da China, como estratégia para baratear os produtos e competir no mercado.

Destacando ainda que, a GAAM, possui uma área construída de 10.000 $\mathrm{m}^{2}$, conta com 174 operários e produz cerca de 30 mil peças por mês.

Outra empresa de grande destaque em Ampére do setor moveleiro é a Movelmar (esta realizou somente importações no período entre 2007 e 2011 máquina circular da Alemanha), que iniciou suas atividades em 2001 e fabrica móveis planejados. Conforme o Sr. Leocir Marafon, diretor da empresa, a Movelmar comercializa seus produtos através de representantes comerciais e as vendas são realizadas para o mercado consumidor por meio de lojas de móveis multimarcas. A empresa conta com frota própria para fazer a 
distribuição dos produtos e, atualmente possui 80 funcionários. Os produtos são comercializados na região Sul e em São Paulo. A comercialização, no Rio Grande do Sul, se dá nas cidades de Bento Gonçalves, Erechim, Passo Fundo, Pelotas, Porto Alegre, Santa Maria e Torres; em Santa Catarina nos municípios de Chapecó, Criciúma, Florianópolis, Joinville, Lages, Lajeado e Tubarão; no Paraná, em Ampére, Cascavel, Curitiba, Foz do Iguaçu, Francisco Beltrão, Londrina e Maringá, além de serem comercializados na cidade de São Paulo.

Já a Krindges Industrial Ltda., figura entre as três maiores indústrias do setor de confecções instaladas na rede de Francisco Beltrão, que como vimos no capítulo anterior iniciou suas atividades em 1977, industrializando-se em 1982 com somente 20 operários, mas que atualmente emprega um total de 1.650 funcionários, com uma produção de 330 mil peças/mês, em sua matriz em Ampére, unidade industrial esta que possui uma área construída de 36 mil $\mathrm{m}^{2}$ e modernos equipamentos, como máquina de corte, enfesto, costura, tinturaria automatizada, entre outras tecnologias.

Conforme o Sr. Luiz Krindges (diretor da indústria), em 2003, a empresa instalou uma filial (unidade industrial) na cidade de São Miguel do Iguaçu - $\mathrm{PR}^{9}$, que conta com 200 funcionários, ampliando sua produção e área de atuação. Atualmente, a empresa conta com as marcas registradas: Aicone, Docthos, Guilherme Ludwer e K\&F. Estes produtos são comercializados por representantes comerciais que realizam vendas para lojistas de praticamente todos os Estados (exceto os Estados do Acre, Amazonas, Roraima e Tocantins) e Distrito Federal e já chegou até a exportar seus produtos para países do Mercosul (destacando que, entre os anos analisados 2007, 2009 e 2011, a empresa não realizou exportações, somente realizou importações). Já a aquisição das matérias-primas se realiza a partir das empresas do Estado de São Paulo: Santista Têxtil da cidade de Tatuí; Têxtil Carvalho e Têxtil Fávero de Americana; além das empresas Horizonte Têxtil de Belo Horizonte - MG e da Têxtil Renault de Brusque - SC. Sem esquecer ainda, que as importações realizadas, desde pelo menos 2007 , foram de tecidos e de artigos acabados da China.

\footnotetext{
${ }^{9}$ A Krindges possui também uma filial (escritório e centro de distribuição) em São Paulo.
} 
Outro fato importante a se destacar é que a Krindges ${ }^{10}$, atualmente, divide em sua capacidade instalada, aproximadamente $70 \%$ para a produção dos artigos próprios e 30\% para terceiros (facção), sobretudo, para artigos destinados as grandes redes varejistas Renner e C\&A. Para esse fato (facção), Rangel (1980) diz que a expansão de uma indústria favorece a instalação de uma seção auxiliar em outra que se liga diretamente a outra indústria. Ou seja, as grandes e pequenas empresas confeccionistas presentes nos centros da rede de Francisco Beltrão, são procuradas por outras empresas, presentes na rede ou em qualquer região do Brasil e solicitam sua prestação de serviços (facção - terceirização) para a realização de partes do processo, como costura, acabamento, produção total, entre outros.

\section{CONSIDERAÇÕES FINAIS}

Ao analisar a dinâmica atual do setor produtivo e suas contemporâneas interações verificou-se que a rede urbana de Francisco Beltrão, na qual se insere Ampére, se torna cada vez mais complexa. $E$, essa complexidade se amplia à medida que se amplia a divisão territorial do trabalho e, com isso, notamos que mesmo cidades locais a exemplo de Ampére, entre outras, realizam interações diretamente com outros países, da América Latina, Europa, África, Ásia etc., ou seja, mantêm relações não apenas com a rede urbana estruturada pela teoria das localidades centrais, mas se estruturam, ao mesmo tempo, em outra rede urbana, deste modo, um dos aspectos desta complexidade diz respeito ao fato de cada cidade situar-se em pelo menos duas redes.

Por exemplo, Ampére mesmo sendo um centro local na área de influência de Francisco Beltrão nos anos 1960 e 1970, cuja dinâmica era dada, sobretudo, pela distribuição da produção rural de bens e serviços, foi nos anos 1990 e 2000 se transformando em um centro especializado na produção industrial moveleira e confeccionista. Deste modo, a cidade se inseriu em diversas relações que dão conta da aquisição de matérias-primas, fluxos de

\footnotetext{
${ }^{10}$ A empresa atua com estoque mínimo. E, realiza a reinserção de aproximadamente $70 \%$ (lucro) na empresa.
} 
mão de obra, produção, distribuição da produção que alcançam todos os Estados brasileiros (concentrando-se no Sul e Sudeste do país) e uma pequena parte da produção é encaminhada para o mercado externo, não nos esquecendo, ainda que, tais relações produzem fluxos de todas as ordens, sobretudo financeiros, responsáveis, principalmente, por manter a dinâmica econômica do centro urbano.

\section{REFERÊNCIAS}

ALEXANDER, J. W. Conceito Básico - Não Básico das Funções Econômicas Urbanas. Boletim Geográfico, n. 203, ano 27, p.34-50, março/abril, 1968.

BESSA, Kelly. A dinâmica da rede urbana no Triângulo Mineiro: Convergências e Divergências entre Uberaba e Uberlândia. Uberlândia: [s.n.], 2007. 348p.

BRASIL. Ministério do Trabalho e Emprego. Programa de Disseminação das Estatísticas do Trabalho. Relação Anual de Informações Sociais (RAIS). Brasília, DF, 1985, 1990, 1995, 2000, 2010. Disponível em $<$ http://bi.mte.gov.br/bgcaged/login.php $>$. Acesso em 20/06/2013.

CASARIL, C. C. A Dinâmica da Rede Urbana de Francisco Beltrão Paraná. 2014. Tese (Doutorado em Geografia). Programa de Pós-Graduação em Geografia. UFSC, Florianópolis.

CORRÊA, R. L.. O sudoeste paranaense antes da colonização. RBG, v.32, n.1, p. 87-98, jan./mar. 1970a. Disponível em <http://biblioteca.ibge.gov.br>. Acesso em 07/06/2007.

Cidade e Região no Sudoeste Paranaense. RBG. v.32, n. 2, p. 3155. 1970b. Disponível em <http://biblioteca.ibge.gov.br>. Acesso em 07/06/2007.

A rede de localidades centrais nos países subdesenvolvidos. Revista Brasileira de Geografia, Rio de Janeiro, v. 50, n. 1, p. 61-83, jan./mar. 1988. Disponível em <http://biblioteca.ibge.gov.br>. Acesso em 08/06/2007.

. Interações Espaciais. In: CASTRO, I. E. de; GOMES, P. C. da C.; CORRÊA, R. L. (Org.). Explorações geográficas: percursos no fim do século. RJ: Bertrand Brasil, 1997' p. 279-318.

Globalização e reestruturação da rede urbana: uma nota sobre as pequenas cidades. Território, Rio de Janeiro, v.4, n.6, p. 43-52, jan./jun. 1999. 2006. 336p.

Estudos sobre a rede urbana. Rio de Janeiro: Bertrand Brasil, CHOLLEY, A. Observações sobre alguns pontos de vista geográficos (part. 1). Boletim Geográfico. Rio de Janeiro: IBGE, n.179, p. 139-145. 1964a. Disponível em <http://biblioteca.ibge.gov.br>. Acesso em 05/08/2008. 
Observações sobre alguns pontos de vista geográficos (part. 2). Boletim Geográfico. Rio de Janeiro: IBGE, n.180, p. 267-276. 1964b. Disponível em <http://biblioteca.ibge.gov.br>. Acesso em 05/08/2008.

CHRISTALLER, W. Central Places in Southern Germany. Prentice-Hall, Inc. Englewood Cliffs, 1966.

DEFFONTAINES, P. Como se constituiu no Brasil a Rede das Cidades. Boletim Geográfico, v.2, n. 14, p. 141-148, maio, 1944.

. Como se constituiu no Brasil a Rede das Cidades II. Boletim Geográfico, v.2, n. 15, p. 299-308, maio, 1945.

ESPÍNDOLA, C. J.; SILVA, M. A. da. Formação Sócio-Espacial: um referencial aos estudos sobre industrialização (notas). Experimental, São Paulo, n. 3, p. 61-67, setembro, 1997.

FLORES, E. L. Industrialização e desenvolvimento no Sudoeste do Paraná. 2009. Dissertação (Mestrado em Geografia). Programa de Pós-Graduação em Geografia. UNIOESTE, Francisco Beltrão.

FRESCA, T. M. Em defesa dos estudos das cidades pequenas no ensino de Geografia. Geografia (Londrina), v. 10, n.1, p.27-34, jan./jun. 2001.

A rede urbana do norte do Paraná. Londrina: Eduel, 2004. 403p.

$\begin{array}{cccccc} & \text { Rede Urbana e Divisão } & \text { Territorial do } & \text { Trabalho. Geografia } \\ \text { (Londrina), } & \text { v.19, } & \text { n.2, } & 2010 . & \text { Disponível } & \text { em }\end{array}$ <http://www.uel.br/revistas/uel/index.php/geografia/>. Acesso em 05/07/2012.

GONÇALVES, J. S. Agronegócio como negócio do município: diretrizes para o progresso local no interior paulista. Informações Econômicas, São Paulo, v.31, n.3, p.55-58, mar. 2001.

IBGE. Regiões de influência das cidades 2007. Rio de Janeiro: IBGE, 2008. 201p. Disponível em <http://www.ibge.gov.br/home/geociencias/geografia/regic.shtm>. Acesso em 12/10/2008.

Censo demográfico - 2010. Rio de Janeiro: IBGE, 2010. Disponível em <http://censo2010.ibge.gov.br/>. Acessado em 12/06/2011.

MARX, K.; ENGELS, F. A ideologia Alemã: Crítica da novíssima filosofia alemã em seus representantes Feuerbach, B. Bauer e Stirner, e do socialismo alemão em seus diferentes profetas, 1845-1846. Rio de Janeiro: Civilização Brasileira, 2007. 643p.

MONBEIG, P. Novos estudos de geografia humana brasileira. São Paulo: Difel, 1957.

RANGEL, I. Recursos ociosos e política econômica. São Paulo: Hucitec, 1980.

SANTOS, Milton. Sociedade e Espaço: A Formação Social como Teoria e como Método. Boletim Paulista de Geografia, São Paulo, n.54, p.81-100, jun. 1977. 
CASARIL, C. C.

A INSERÇÃO DA CIDADE PEQUENA DE AMPÉRE - PR NA REDE URBANA A PARTIR DA DINÂMICA INDUSTRIAL

A urbanização brasileira. São Paulo: Hucitec, 1993. 